\title{
AWARENESS ABOUT SEBORRHEIC DERMATITIS AMONG CHENNAI POPULATION: A SURVEY
}

\section{*Vaishnavi Sivakali Subramanian}

*BDS, Saveetha Dental College and Hospital

\section{A R T I C L E I N F O}

\section{Article History:}

Received $18^{\text {th }}$ December, 2016

Received in revised form $16^{\text {th }}$ January, 2017

Accepted $26^{\text {th }}$ February, 2017

Published online $28^{\text {th }}$ March, 2017

\section{Key words:}

Seborrheic dermatitis (SD), dandruff, treatment, Causes, investigations

\begin{abstract}
A B S T R A C T
AIM: To create awareness about seborrheic dermatitis among Chennai population.

Materials and method: The survey was carried out by preparing a set of questionnaires. These questionnaires were circulated among subjects to determine their awareness about Seborrheic dermatitis. The sample size for this survey was 100. Data collected was then analysed statistically with the help of SPSS online software.

RESULTS: Present study came out with a result of $62 \%$ were not aware about SD and $38 \%$ were reported to be aware. But all the subjects were aware what a dandruff is about. While evaluating the cause factor awareness for SD $47 \%$ were aware about causes leading to SD while $53 \%$ were not educated about it.37\% population believed that dry and cold weather to be major cause for SD and $22 \%$ reported stress can also trigger the cause for $\mathrm{SD}$. Diagnostic investigation knowledge were also seem to be less among the subjects for $27 \%$, skin biopsy technique being used to diagnose SD was known only to $23 \%$. Various treatment options are there for treating the seborrheic dermatitis, but only antifungal and corticosteroid preparations were most prevailing among the subjects.
\end{abstract}

CONCLUSION: From this study, we can conclude that the subjects were aware about dandruff but were not aware about the difference between SD and dandruff.

Copyright $\odot 2017$ Vaishnavi Sivakali Subramanian et al. This is an open access article distributed under the Creative Commons Attribution

License, which permits unrestricted use, distribution, and reproduction in any medium, provided the original work is properly cited.

\section{INTRODUCTION}

Seborrheic Dermatitis (SD) and dandruff are common dermatological problems that affect the seborrheic areas of the body. They are considered the same basic condition sharing many features and responding to similar treatments, differing only in locality and severity. Dandruff is restricted to the scalp, and involves itchy, flaking skin without visible inflammation. SD affects the scalp as well as face, retroauricular area, and the upper chest, causing flaking, scaling, inflammation and pruritus, and can have marked erythema. Flaking in SD and dandruff is usually white-to-yellowish, and may be oily or dry (1). The pathogenesis of SD is still unclear, but it seems to be multifactorial, involving sebaceous gland function, the presence on the skin of yeasts belonging to Malassezia s pp. (formerly called Pityrosporumovale), and the individual immunological response (2-4). Although the fundamental cause of seborrheic dermatitis has not yet been established, many etiologic factors are believed to play a role in the development of the disorder (5). Available treatments for scalp SD are intended to eradicate Malassezia spp. and to reduce inflammation and scaling (6-8).

*Corresponding author: Vaishnavi Sivakali Subramanian BDS, Saveetha Dental College and Hospital,
Topical therapies are the mainstay of treatment as the condition is recurrent and responds well to these agents (9).In order to evaluate the knowledge about SD among Chennai population, this survey was carried out.

\section{METHODS}

The survey was carried out by preparing a set of questionnaires. These questionnaires were circulated among subjects to determine their awareness about Seborrheic dermatitis. The sample size for this survey was 100, which includes various age group. Data collected was then analysed statistically with the help of SPSS online software.

Before starting the survey, informed consent were taken from subjects.

\section{RESULTS AND DISSCUSSION}

Present study came out with a result of $62 \%$ were not aware about SD and $38 \%$ were reported to be aware. While evaluating the cause factor awareness for SD 58\% were aware about causes leading to SD while $42 \%$ were not educated about it.37\% population believed that dry and cold weather to be major cause for $\mathrm{SD}$ and $22 \%$ reported stress can also trigger the cause for $\mathrm{SD} ; 21 \%, 11 \%$ reported as medical conditions and inflammatory response related to psoriasis. Even genes play a role in triggers as reported by $9 \%$ of 
population. $82 \%$ even reported that even allergy or even unclean environment can also be a reason for SD.
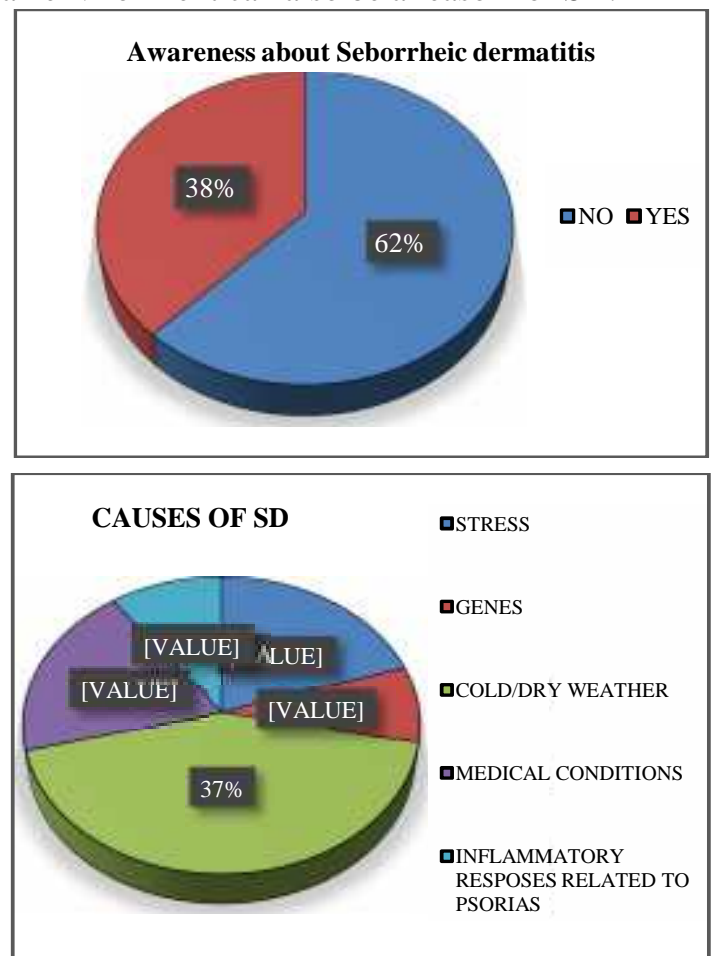

According to our study, Adults ranging from 30-60 showed high prevalence of SD, followed by in adolescents and ten by children, which also showed age also played a role that is decrease in age deceases the prevalence of SD. Clinical signs and symptoms are important to diagnose a disease, taking this fact to the subject, whom reported that $58 \%$ of them were educated about the symptoms. But skin flakes and itching came out as the most common symptoms seen among the subjects which was $47 \%$ and $32 \%$ respectively. Even though $38 \%$ were aware what is SD but failed to know that SD can affect even areas other than scalp which turned out to be $72 \%$
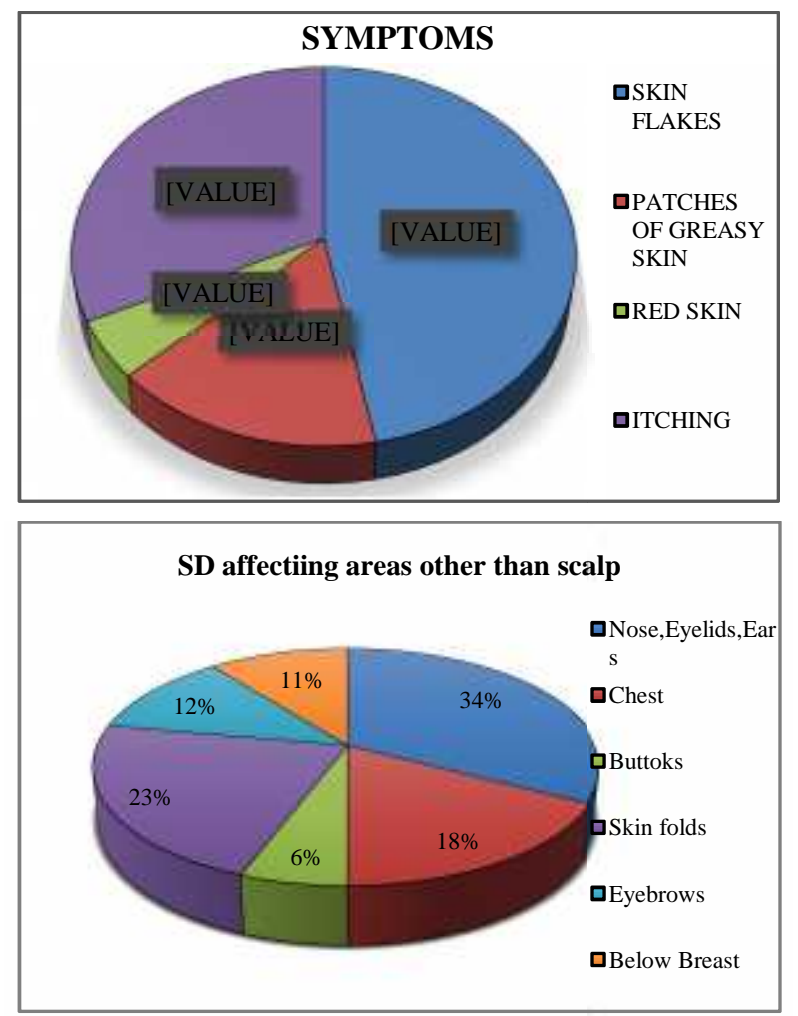

Diagnostic investigation knowledge were also seem to be less among the subjects for $27 \%$, skin biopsy technique being used to diagnose SD was known only to $23 \%$. Various treatment options are there for treating the seborrheic dermatitis, but only antifungal and corticosteroid preparations were most prevailing among the subjects. Even though many allopathically successive treatments available, this study showed $74 \%$ of the subjects prefer herbal remedies, in which aloe vera and lemon was commonly used or preferred among the subjects.
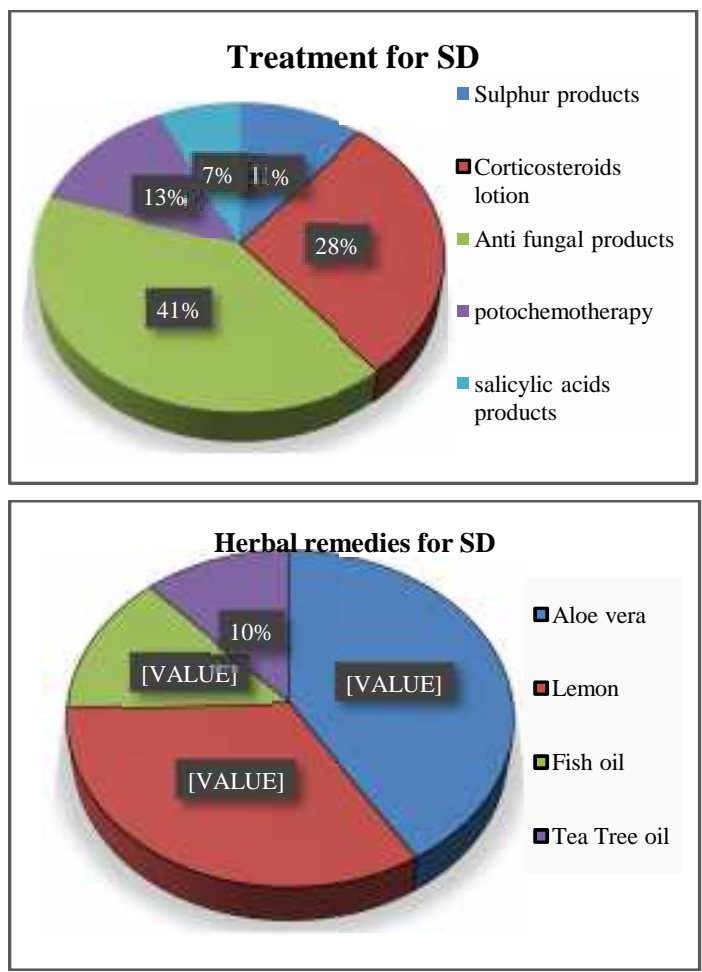

\section{CONCLUSION}

From this study we can conclude that the subjects were aware about dandruff but were not aware about the difference between SD and dandruff.

\section{Reference}

1. Luis J. Borda and Tongyu C. Wikramanayake (2015) 'Seborrheic Dermatitis and Dandruff: A Comprehensive Review', J Clin Investig Dermatol, 3(2).

2. BukvićMokos Z, Kralj M, Basta-Juzbašić A, LakošJukić I: Seborrheic dermatitis: an update. Acta Dermatovenerol Croat 2012; 20: 98104.

3. Dessinioti C, Katsambas A: Seborrheic dermatitis: etiology, risk factors, and treatments: facts and controversies. ClinDermatol 2013; 31: 343-351.

4. Gary G: Optimizing treatment approaches in seborrheic dermatitis. J Clin Aesthet Dermatol 2013; $6 ; 44-49$

5. 1. Del Rosso JQ. Adult seborrheic dermatitis: a status report on practical topical management. J ClinAesthetDermatol 2011; 4: 32-8.

6. Hald M, Arendrup MC, Svejgaard EL, Lindskov R, Foged EK, Saunte DM: Evidence-based Danish guidelines for the treatment of Malassezia- related skin diseases. Acta DermVenereol 2015; 95: 12-19. 
7. Bhatia N: Treating seborrheic dermatitis: review of mechanisms and therapeutic options. $J$ Drugs Dermatol 2013; 12:796-798.

8. David E, Tanuos H, Sullivan T, Yan A, Kircik LH: A double-blind, placebo-controlled pilot study to estimate the efficacy and tolerability of a nonsteroidal cream for the treatment of cradle cap (seborrheic dermatitis). J Drugs Dermatol 2013; 12: 448-452.

9. Stefanaki I, Katsambas A: Therapeutic update on seborrheic dermatitis. Skin Therapy Lett 2010; 15: $1-4$.

\section{Please cite this article in press as:}

Vaishnavi Sivakali Subramanian (2017), Awareness about seborrheic dermatitis among chennai population: a survey, International Journal of Current Advanced Research, 6(03), pp. 3017-3019. http://dx.doi.org/10.24327/ijcar.2017.3019.0166 